\title{
Ancient Ocean Crossings: Reconsidering the Case for Contacts with the Pre-Columbian Americas. By Stephen C. Jett. 2017. The University of Alabama Press, Tuscaloosa. 508 pp.
}

\author{
Diana Rocío Carvajal Contreras ${ }^{1^{*}}$ \\ ${ }^{1}$ Facultad de Estudios de Patrimonio Cultural, Carrera de Arqueología, Universidad Externado de Colombia, Bogotá, \\ Colombia. \\ *diana.carvajal@uexternado.edu.co
}

Received June 27, 2018

OPEN ӘACCESS

Accepted September 29, 2018

DOI 10.14237/ebl.9.2.2018.1352

Copyright @ 2018 by the author(s) licensee Society of Ethnobiology. This is an open-access article distributed under the terms of the Creative Commons Attribution-NonCommercial 4.0 International Public License (https://creativecommons.org/licenses/by-nc/4.0), which permits non-commercial use, distribution, and reproduction in any medium, provided the original author and source are credited.

Stephen Jett's Ancient Oceans Crossings is a complete, simple, and straightforward text that compiles historical and archaeological information about transoceanic contacts between the Western and Eastern hemispheres before 1492.

The book is a first step towards revising several lines of evidence and ideas surrounding sea trips and pre-Columbian contacts. This very personal book not only shows the development of Stephen Jett's academic life and motivations, but also transforms this author into a generalist social scientist interested in the diverse disciplines of anthropology, history, climatology, genetics, navigation, and several others. The story of his life, partially revealed in this book, led to questions about and academic inquiries into the cultural similarities observed in different human groups across oceans.

The author relates his experiences to academic influences in the preface. In the first paragraphs, Jett emphasizes, in a modest way, that his purpose is not to review the theory of culture history or return to the notion of diffusion as an explanatory tool. Jett approaches the problem of inter-oceanic contacts, using a "forensic" approach where he collects abundant evidence of these interactions, emphasizes navigation capabilities, and reasons for crossing the oceans. However, I believe Jett makes hyperdiffusionist theoretical claims and sets out to support a personal belief. He aims to show similarities in traits or cultural characteristics of certain human groups and their subsequent transmission to other cultures made through sea contacts. This disregards other mechanisms that could explain these similarities. He does, however, consider some ecological and social dynamics to strengthen his case for why similarities occur.

The author wants to "destigmatize" the concept of cultural diffusion and allow multiple specialists to discuss and consider the evidence for contact in a more creative way. Thus, Jett not only proposes the possibility of independent developments, but also hypothesizes that this diffusion is the result of contact between populations. I agree with Jett, both in the present and in the past, the transfer of information occurred between different social groups and was an important factor in cultural evolution. However, theorists in archeology and anthropology have highly debated the presence of artifacts and ideas in places that are thought to not have had contact. Some of these ideas or objects are intrinsic impulses of human nature that developed in parallel; for others, they are the products of internal social contradictions or due to environmental influences; finally, some scientists believe that these innovations are independent results of human agency (Storey and Jones 2011). Both Jett's approach and other approaches to the presence of ideas, artifacts, and other cultural features use a reductionist view to approach the complexity of cultural evolution. My personal view is that human activities and cultural evolution are not only responses to stimuli, but are the satisfaction of biological needs or a search to establish equilibrium. Human activities and the transmission of information and therefore culture evolution must be understood as part of 
complex and open dynamic systems. Diverse interactions between humans involve adaptation to the environment and over time, human groups are interwoven with others in increasingly complex interactions that imply acceptance or rejection of artifacts, ideas, and technologies in unpredictable ways, which set diverse cultural trajectories (Bentley and Maschner 2007).

In the first section, Intellectual Obstacles to the Notion of Early Transoceanic Contacts, the author reflects on common perceptions about transoceanic contacts between the Old and New Worlds. These preconceptions are related to the consideration that the pre-Columbian human groups did not have the technical skills to navigate or the motivation or the geographic knowledge to carry out long-distance trips. $\mathrm{He}$ shows that these ideas originate with contemporary scientists' and not historical, including Christopher Columbus' contemporaries, who imposed not only geographical barriers, but also ideas to human movements in the past. In this first part, Jett provides information about how populations might have had knowledge of the ocean currents, weather conditions, how to stay alive while on high seas, and mentions a number of cases of accidental trips overseas. He argues using a transdisciplinary approach with data of the absence or presence of diseases, domestic resources, or technological developments that respond to the inter-oceanic contacts between groups. Jett also suggests the acceptance or rejection of such elements in very particular social and historical contexts. Moreover, he discusses the reason for the inconsistency of data. On the one hand, the problems of preservation, the nature of the evidence of these contacts, and the silence of the historical record show the discontinuity of the records. On the other, he points out the problems to evaluate the existence or the extent of contacts between human groups of both hemispheres, which is due to lack of a characterization of what objects and practices are diagnostic to identify these exchanges and the implications of those exchanges to understand cultural evolution.

In the second part, Means: The Types and Availabilities of $W$ atercraft and Navigation, his purpose is to counter our "terrestrial" and Eurocentric vision of the world by showing us the environmental knowledge required for the construction of boats and navigation skills required to cross the oceans. The author proposes to reevaluate trips such as those undertaken by Homo erectus and the Pre-Norse and Columbian journeys. He summarizes different types of boats used in the past - their advantages and technical limitations-strategies for compass and star navigation, and the use of reference points such as the color of seawater and knowledge of atmospheric patterns and animal behaviors.

The next section, Motives for Ocean Crossings, systematically evaluates the reasons why human groups chose inter-oceanic trips. This is a problematic topic but the author tries to understand the mentalities of the human groups that were pushed or pulled to make forays into these "liquid territories" by religious, political, social, and natural phenomena. This series of chapters show that in the past and now, global interconnectedness has promoted and accelerated migration.

The fourth section, Opportunity and Exchange, is specifically about the concrete evidence for interoceanic contact. The organized and updated data present the facts of those sea contacts suggesting other times and locations in Asia, America, and Australia and suggest broad impacts at the cultural level and the translocation of plants and animals. The linguistic, artifactual, biological, pathological, and genetic evidence is used to try to establish differences and similarities present in interactions of human groups in both hemispheres. With multiple lines of evidence from the remains themselves, texts, and iconographic representations, Jett encourages readers to check their common sense with the presence of domestic animals, diseases, parasites, cultigens, and hallucinogenic plants on both sides of the Atlantic and critically rethink beliefs that human beings were unknown to each other in the past. He pinpoints the recent molecular evidence of group movements and treponematosic diseases, which are evidence of historical relationships between populations on a global scale.

No one method for interpreting the past-in this case, inter-oceanic travel-works for all historical cases. For Jett, cultural developments are explained by diffusion. For the vast majority of historians and archaeologists, this explanation for the dissemination of knowledge and technology is viewed with caution in the best of cases and seen with skepticism in the case of inter-oceanic contacts before the Vikings. It is criticized as a vision of being biased by the notion of cultural evolution (Fagan 2006; Kehoe 2003; Storey and Jones 2011). For historians, archaeologists, 
geographers, and other scientists, this book allows us to revisit how we understand development and change in human groups and the theoretical frameworks with which we analyze them.

In conclusion, this book revisits some questions: Is the presence of cultural artifacts in common a result of innovative creation or are they copies of other cultures? Do we understand societies as isolated entities or as a network of relationships? How should we include environments in our understanding of cultural change?

\section{References Cited}

Bentley, R., and H. Maschner. 2007. Complexity Theory. In Handbook of Archaeological Theories, edited by $\mathrm{H}$. Bentley, H. Maschner, and C. Chippendale, pp. 245-270. Altamira Press, Lanham, MD.
Fagan, G. 2006. Archaeological Fantasies: How Pseudoarchaeology Misrepresents the Past and Misleads the Public. Routledge, London.

Kehoe, A. 2003. The Fringe of American Archaeology: Transoceanic and Transcontinental Contacts in Prehistoric America. Journal of Scientific Exploration 17:19-36.

Storey, A., and T. Jones. 2011. Diffusionism in Archaeological Theory: The Good, the Bad, and the Ugly. In Polynesian in America: Pre-Columbian Contacts with the New World, edited by T. Jones, A. Storey, E. Matisoo Smith, and J. Ramirez Aliaga, pp. 7-24. Altamira Press, Lanham, MD. 